\title{
Successful weaning from mechanical ventilation in the quadriplegia patient with C2 spinal cord injury undergoing C2-4 spine laminoplasty -A case report-
}

\author{
Jee-Eun Chang ${ }^{1}$, Sang-Hyun Park ${ }^{2}$, Sang-Hwan Do $^{2}$, and In Ae Song ${ }^{2}$ \\ Department of Anesthesiology and Pain Medicine, ${ }^{1}$ Seoul National University Hospital, Seoul, ${ }^{2}$ Seoul National University Bundang \\ Hospital, Seongnam, Korea
}

In patients with cervical spine injuries, respiratory function requires careful attention. Voluntary respiratory control is usually possible with lesions below $\mathrm{C} 4$ level although paralysis of the abdominal musculature results in a decreased ability to cough and to clear secretions, which may later lead to respiratory insufficiency. Therefore, injuries above C5 usually necessitate long term mechanical ventilation. Even though weaning criteria are not definitive for the quadriplegic patient, M-mode ultrasonography of the diaphragm may be useful in identifying patients at high risk of difficulty weaning. Diaphragmatic dysfunction (vertical excursion $<10 \mathrm{~mm}$ or paradoxical movements) results in frequent early and delayed weaning failures. We present our clinical experience with successful weaning by using M-mode ultrasonography and a cough-assist device for secretion clearance after extubation in a quadriplegic patient undergoing C2-4 spine laminoplasty. (Korean J Anesthesiol 2013; 64: 545-549)

Key Words: Cervical spinal injury, Quadriplegia, Ventilator weaning.

Respiratory complications are common in the cervical spinal cord-injured patient. Patients with injuries above C3 usually have sequelae of impaired inspiratory and expiratory function [1] because the inspiratory muscle in diaphragm is innervated from C3-C5 and the expiratory muscles are innervated from T7-L1 [2]. Even in patients with normal diaphragm function, the clearance of secretions may be impaired due to paralysis of the trunk and abdominal muscle [3]. These complications frequently make the use of long-term mechanical ventilation necessary in patients with C-spine cord injuries above C5 [1]. We report on a case of successful weaning from mechanical ventilation in a quadriplegic patient with $\mathrm{C} 2$ spinal cord injury undergoing C2-4 spine laminoplasty. His diaphragmatic dysfunction was checked by using M-mode ultrasonography before ventilator weaning and a cough-assist device was applied after extubation.

Received: April 24, 2012. Revised: August 1, 2012. Accepted: August 20, 2012.

Corresponding author: Sang-Hyun Park, M.D., Department of Anesthesiology and Pain Medicine, Seoul National University Bundang Hospital, 166, Gumi-ro, Bundang-gu, Seongnam 463-707, Korea. Tel: 82-31-787-7499, Fax: 82-31-787-4063, E-mail: psh1399@snnubh.org

(c) This is an open-access article distributed under the terms of the Creative Commons Attribution Non-Commercial License (http:// creativecommons.org/licenses/by-nc/3.0/), which permits unrestricted non-commercial use, distribution, and reproduction in any medium, provided the original work is properly cited. 


\section{Case Report}

A 65 year-old male patient, $157 \mathrm{~cm}$ in height and $59.4 \mathrm{~kg}$ in weight was transferred to the emergency department from another hospital for a C2-4 spine laminoplasty while intubated. He had a traffic accident 5 days ago. He was alert but diagnosed with near complete quadriplegia with respiratory muscle weakness. His cervical spine MRI showed cord contusion and grade 3 central canal stenosis at $\mathrm{C} 2 / 3, \mathrm{C} 3 / 4$ with ossification of the posterior longitudinal ligament at C2-3 level (Fig. 1). Initial vital signs were systolic blood pressure (SBP) 107 $\mathrm{mmHg}$, diastolic blood pressure (DBP) $54 \mathrm{mmHg}$, heart rate (HR) 62 beats/min, respiratory rate (RR) 18 times/min, $\mathrm{SpO}_{2}$ $100 \%$. In the neurologic examination, the motor power in the whole spine level was grade 0 . The sensory for light touch was intact at both $\mathrm{C} 2-\mathrm{T} 5$ levels, but below $\mathrm{T} 5$ was insensible. The sensory for pin prick was intact except both $\mathrm{C} 2-4$ levels and the brainstem reflex was intact. The ventilator was applied with volume controlled ventilation (VCV) mode set at tidal volume (TV) $400 \mathrm{ml}$, fraction of inspired oxygen $\left(\mathrm{FiO}_{2}\right)$ 0.3, positive endexpiratory pressure (PEEP) $5 \mathrm{cmH}_{2} \mathrm{O}$, frequency 14 times/min. Dopamine continuous infusion was started with $5 \mathrm{mcg} / \mathrm{kg} / \mathrm{min}$.

In the preoperative evaluation, the patient's chest X-ray, electrocardiogram and laboratory examination showed no abnormal findings. Six days after the traffic accident, he underwent C2-4 laminoplasty. Upon arrival at the operation room, noninvasive monitoring (arterial blood pressure cuff, pulse oximeter, electrocardiography) were attached. To induce anesthesia, $60 \mathrm{mg}$ of propofol and $40 \mathrm{mg}$ of rocuronium were injected intravenously and blood pressure was monitored by

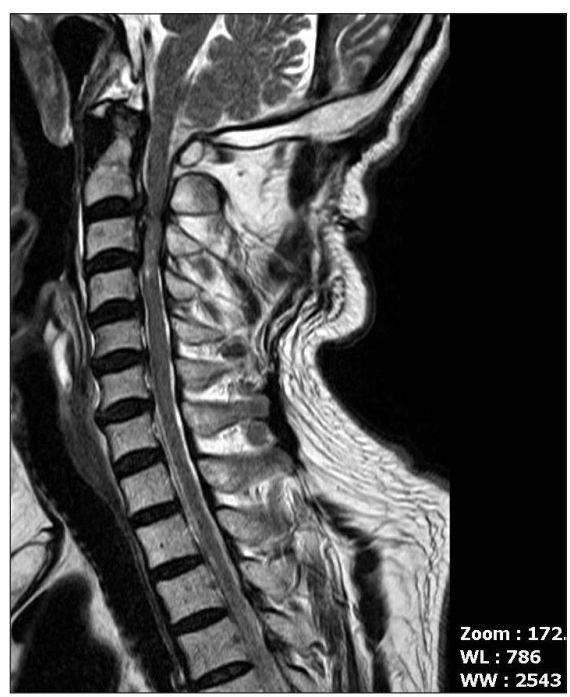

Fig. 1. A MRI showing the cord contusion and grade 3 central canal stenosis at $\mathrm{C} 2 / 3, \mathrm{C} 3 / 4$ with ossification of posterior longitudinal ligament at C2-3 level. placing an arterial line. Anesthesia was maintained with 50\% $\mathrm{O}_{2}$ (mixed with air), sevoflurane $2.0-2.5 \%$, and remifentanil $0.05-0.10 \mathrm{mcg} / \mathrm{kg} / \mathrm{min}$. The patient was placed in prone position. Dopamine was infused continuously with $2-5 \mathrm{mcg} /$ $\mathrm{kg} / \mathrm{min}$ throughout the surgery and the patient's vital signs were maintained within the normal range. Blood loss was approximately $550 \mathrm{ml}$ and urine output was $70 \mathrm{ml}$. The total amount of fluids administered was $1,300 \mathrm{ml}$ of crystalloid solution and $900 \mathrm{ml}$ of colloid solution. The operative time was 4 hours and $30 \mathrm{~min}$. After the surgery ended, the patient was transferred to the intensive care unit (ICU) with bagging with bag-valve-mask (Ambu bag) via the endotracheal tube.

In the intensive care unit, his initial vital signs were blood pressure 132/58 mmHg, HR 70 beats/min, $\mathrm{SpO}_{2}$ 100\%. Dopamine continuous infusion was kept with $5 \mathrm{mcg} / \mathrm{kg} / \mathrm{min}$. The ventilator was set as synchronized intermittent mandatory ventilation (SIMV) mode with pressure control (PC) $19 \mathrm{cmH}_{2} \mathrm{O}$, $\mathrm{FiO}_{2}$ 0.5, PEEP $5 \mathrm{cmH}_{2} \mathrm{O}$, frequency 10 times/min. On postoperative day 1 , self respiration was detected and the ventilator setting of SIMV mode was changed to $\mathrm{PC} 16 \mathrm{cmH}_{2} \mathrm{O}, \mathrm{FiO}_{2} 0.3$, frequency 8 times/min, pressure support (PS) $7 \mathrm{cmH}_{2} \mathrm{O}$, PEEP $5 \mathrm{cmH}_{2} \mathrm{O}$. The tidal volume was checked as $400-500 \mathrm{ml}$ during pressure control period and $200-300 \mathrm{ml}$ during PS period and his abdominal movement was paradoxical when he breathed spontaneously.

On postoperative day 2, we examined the diaphragmatic movement of the patient in supine position to evaluate probability of weaning from mechanical ventilation by using M-mode ultrasonography (Vividi, General Electronic Company, USA). At the start of 1-hr spontaneous breathing test, a 3.5$\mathrm{MHz}$ US probe (3S-RS probe) was placed over one of the intercostal spaces in the right posterior axillary line for the right diaphragm and the midaxillary line for the left diaphragm. The

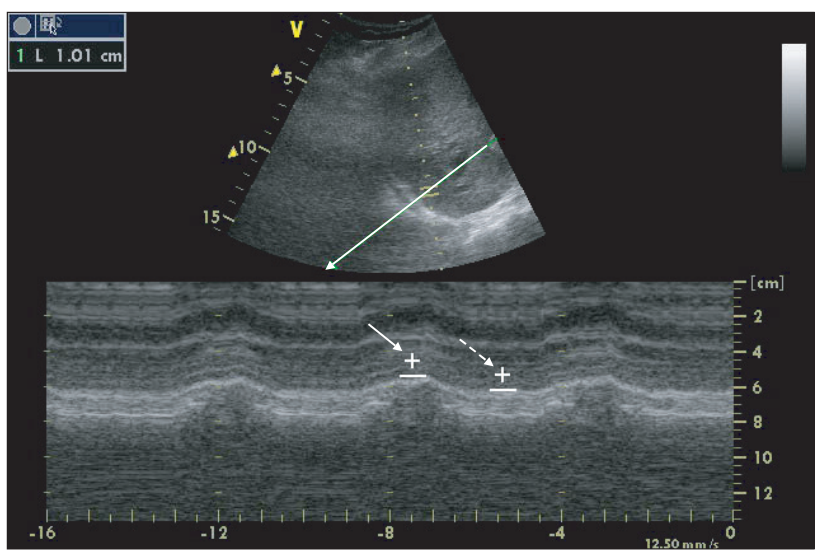

Fig. 2. A M-mode ultrasonography showing right diaphragmatic excursion showing an inspiratory peak (lined arrow) above the baseline (dotted arrow). The vertical excursion of diaphragm was $15 \mathrm{~mm}$. 
liver or spleen was used as a window for each hemidiaphragm. The ultrasound beam was directed to the hemidiaphragmatic domes at an angle of not $<70^{\circ}$ and rotated to be perpendicular to the domes by an anatomical M-mode. The amplitude of excursion was measured on the vertical axis of the tracing from the baseline to the point of maximum height of inspiration on the graph. Six measurements were recorded and averaged for each side and the vertical excursion of diaphragm was $15 \mathrm{~mm}$ (Fig. 2). He had clear consciousness with adequate cough reflex and stable cardiovascular function. The rapid shallow breathing index (respiratory rate/TV) was 66.7 and oxygen saturation was $99 \%$ in $\mathrm{FiO}_{2} 0.3$ and partial pressure of carbon dioxide $\left(\mathrm{PaCO}_{2}\right)$ was $43 \mathrm{mmHg}$. Thereafter, extubation was done.

After extubation, $\mathrm{O}_{2} 5 \mathrm{~L} / \mathrm{min}$ was applied via facial mask with partial rebreathing reservoir and he was observed closely. Thirty minutes later, the arterial blood gas analysis was $\mathrm{pH}$ 7.458, $\mathrm{PaCO}_{2} 40.5 \mathrm{mmHg}$, partial pressure of oxygen $\left(\mathrm{PaO}_{2}\right)$ $275.7 \mathrm{mmHg}$, bicarbonate $\left(\mathrm{HCO}_{3}{ }^{-}\right) 28.9 \mathrm{mmHg}$. For preventing secretion retention, we used a cough-assist device (CA-3200, J.H. Emerson Co., Cambridge, MA, USA) with the help of a rehabilitation doctor. Its setting was positive $20 \mathrm{cmH}_{2} \mathrm{O}$ pressure, negative $40 \mathrm{cmH}_{2} \mathrm{O}$ pressure. It was applied for twenty minutes each time and suction was performed four times per day by the rehabilitation doctor.

He was stable with SBP 100-130 $\mathrm{mmHg}$, DBP 45-55 $\mathrm{mmHg}$, HR 50-65 beats $/ \mathrm{min}$ under $5-10 \mathrm{mcg} / \mathrm{kg} / \mathrm{min}$ dopamine continuous infusion. The RR was 15-25 times/ min and oxygen saturation was $97-100 \%$. Arterial blood gas analysis was maintained as $\mathrm{pH} 7.35-7.4, \mathrm{PaCO}_{2} 40-50 \mathrm{mmHg}$, $\mathrm{PaO}_{2}$ 170-190 mmHg, HCO3- 29-29.5 mmHg with $\mathrm{O}_{2} 5 \mathrm{~L}$ via facial mask and intermittent cough-assist device, from 2 hours after extubation for 5 days. He was transferred to his hometown hospital 5 days after extubation.

\section{Discussion}

Particular attention should be given to the respiratory system function in patients with cervical spinal cord injuries. For most of these patients, the need for definitive airway control, early intubation, tracheostomy, and ventilator dependence is significant [1]. A study by Claxton et al. [2] found that spinal cord injuries of C5 and above neurologic levels predicted need for mechanical ventilation. Harrop et al. [4] demonstrated that $79 \%$ of their complete spinal cord injuries with a neurologic level of C5 and above received tracheostomy.

The main muscle generating the negative intrathoracic pressure that produces inspiration is the diaphragm, which innervation is from the phrenic nerves (C3-5). Additional inspiratory efforts are produced by the external intercostal muscles innervated by their intercostals nerves T1-12 and the accessory muscles, consisting of sternomastoid (accessory nerve, C1-2), trapezius (C1-4), scalene, and pectoralis (C4-8) muscles. Inspiration involves contraction of the diaphragm and the external intercostal muscles, which allow the chest wall to expand. The accessory muscles are recruited to aid in this process at high levels of activity. The expiratory muscles are the internal and external oblique muscles (T7 to T12), the transverse abdominus (T7 to L1), the rectus abdominus ( $\mathrm{T} 7$ to $\mathrm{L} 1$ ), and the lateral intercostal muscles ( $\mathrm{T} 1$ to $\mathrm{T} 12$ ). Expiration is mostly passive but can be augmented in this process by the abdominal musculature [3]. Therefore, patients with injuries above C3 have complete loss of inspiratory and expiratory capacity. In addition, paralysis of the abdominal musculature will also result in a decreased ability to cough and to clear secretions, which may later lead to respiratory insufficiency [1]. For theses reasons, neurological level influences the rate of ventilator weaning, with greater than $85 \%$ success in weaning at levels C4 and below, $60 \%$ success at C3, $28 \%$ at $\mathrm{C} 2$, and $15 \%$ at $\mathrm{C} 1$ [5]. Determination of C2 level is based on the American Spinal Injury Association (ASIA) impairment scale. This determination coincides with the diaphragm dysfunction. However, if the sensory tract was impaired in topography of spinal cord, it is possible that there was the normal diaphragm function or partial impairment in our case report.

There are no studies or clear clinical guidelines regarding criteria for weaning and extubation after high cervical spinal cord injury. A vital capacity (VC) of more than $10 \mathrm{ml} / \mathrm{kg}$, RR (12-20 breaths/min), minute ventilation ( $<10 \mathrm{~L} / \mathrm{min}), \mathrm{PaO}_{2}$ more than $80 \mathrm{mmHg}$ with $\mathrm{FiO}_{2}$ at $0.4, \mathrm{PaCO}_{2}$ less than $45 \mathrm{mmHg}$ and rapid shallow breathing index of less than 105 beats/ $\mathrm{min} / \mathrm{L}$ [6] are frequently recommended weaning parameters in general population. These measurements have not been validated in quadriplegics. The usefulness of these common parameters in respiratory decision making for quadriplegics should be carefully evaluated in a large study. There are some studies about predictors of ventilator weaning in individuals with high cervical spinal cord injury. A retrospective review found that 7 of 33 patients with $\mathrm{C} 1$ to $\mathrm{C} 4$ spinal cord injury and diaphragmatic paralysis weaned from the ventilator in 40 to 292 days. In that study, data such as fluoroscopic examination of the diaphragm and spirometry results were used prospectively in the evaluation of ventilator-dependent patients [7]. A retrospective study by Chiodo et al. [8] revealed negative inspiration force diaphragm needle electromyography (EMG) best predicted the ability to wean from the ventilator, and spirometry (negative inspiratory force and forced vital capacity) to be an accurate bedside measure of a patient's readiness to wean. In recent studies, M-mode ultrasonography of the diaphragm may be useful in identifying patients at high risk of difficulty weaning. Diaphragmatic dysfunction (vertical excursion $<10$ 
mm or paradoxical movements) is predictive of frequent early and delayed weaning failures [9].

The patient in this case had quadriplegia with a C2 spinal cord injury and his neurologic deficit was not improved despite C2-4 laminoplasty. He should receive tracheostomy and ventilation care according to studies of Claxton et al. [2] and Harrop et al. [4], but he strongly rejected tracheostomy. For the sake of ventilator weaning, his diaphragmatic movement was measured by using M-mode ultrasonography. He was able to be weaned from ventilator successfully owing to intact movement of his diaphragm checked by ultrasonography, even though he has complete spinal cord injuries with a neurologic level of C2.

His abdominal movement was paradoxical, indicating paralysis of the abdominal musculature. Adequate expiratory muscle function is critical for clearing airway secretions and bronchial mucous plugs. During periods of respiratory tract infection (RTI) or profuse airway secretion, peak cough expiratory flows (PCEFs) must be adequate to prevent mucous plugging and pulmonary complications [10]. The VC, FVC, and PCEF are decreased during RTIs because of fatigue, respiratory musculature weakening, and mucous plugging [10]. When inadequate, the most effective alternative for generating optimal PCEF and clearing deep airway secretions is the use of mechanical insufflation-exsufflation (MI-E) [11]. MI-E has been shown of value in decreasing hospitalization rates for respiratory complications of neuromuscular disease [12]. A case in 2002 reported the successful perioperative management of an 11-year-old boy with type II spinal muscular atrophy undergoing a single-stage posterior spinal fusion procedure. Use of an MI-E device was able to successfully treat sputum retention and avoid a tracheostomy [13]. Utilization of mechanical in-exsufflation has produced positive outcomes in

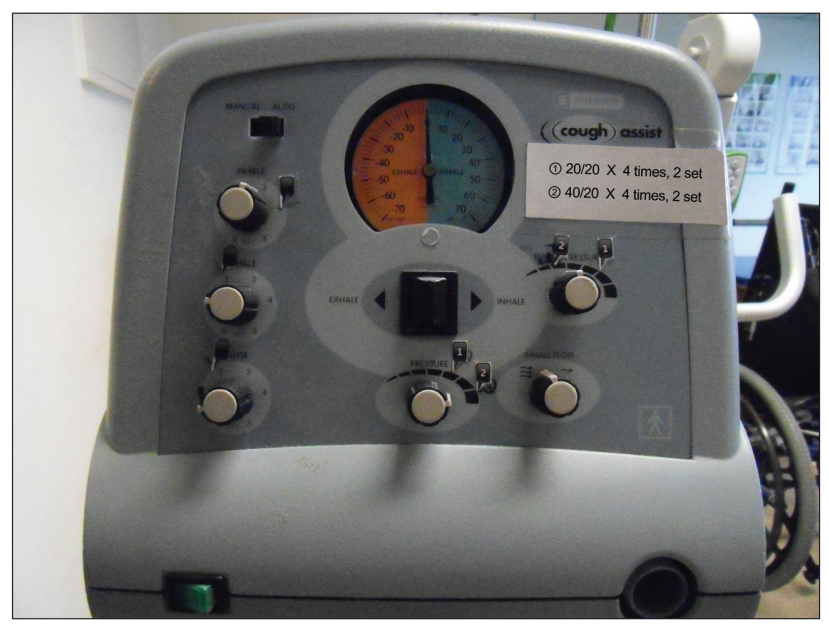

Fig. 3. A cough-assist device. It is designed to make patient's cough vigorous after extubation. Its setting was positive $20 \mathrm{cmH}_{2} \mathrm{O}$ pressure, negative $40 \mathrm{cmH}_{2} \mathrm{O}$ pressure. terms of patient satisfaction, low rates of ventilator-acquired pneumonia, low incidence of complications, and ease of home discharge with patient or family using the device long term in spinal cord injury patients [14].

The MI-E that we used is the Emerson CoughAssist ${ }^{\mathrm{TM}}$ Mechanical In-Exsufflator (Fig. 3). It has both a manual and an automatic mode, such that cycling from insufflation to exsufflation may be manually controlled or automatic. Each cycle comprises insufflation, then exsufflation, followed by a pause, at which the machine returns to atmospheric pressure. The pressures are generated by a two-stage centrifugal blower [13]. The positive and negative pressures may be set for insufflation and exsufflation up to a maximum of $60 \mathrm{cmH}_{2} \mathrm{O}$. Each insufflation and exsufflation is usually $2-3$ second.

In summary, this case report demonstrates successful weaning from mechanical ventilation in a quadriplegic patient with C2 spinal cord injury undergoing C2-4 spine laminoplasty. Use of M-mode ultrasonography for checking diaphragmatic movement was able to predict ventilator weaning. Apply of an MI-E device can treat sputum retention successfully and avoid a tracheostomy and mechanical ventilation.

\section{References}

1. Como JJ, Sutton ER, McCunn M, Dutton RP, Johnson SB, Aarabi B, et al. Characterizing the need for mechanical ventilation following cervical spinal cord injury with neurologic deficit. J Trauma 2005; 59: 912-6.

2. Claxton AR, Wong DT, Chung F, Fehlings MG. Predictors of hospital mortality and mechanical ventilation in patients with cervical spinal cord injury. Can J Anaesth 1998; 45: 144-9.

3. Valadka A, Andrews B. Neurotrauma: Evidence-based answers to common questions. New York, ThiemeMedical Publishers, Inc. 2005, p 213.

4. Harrop JS, Sharan AD, Scheid EH Jr, Vaccaro AR, Przybylski GJ. Tracheostomy placement in patients with complete cervical spinal cord injuries: American Spinal Injury Association Grade A. J Neurosurg 2004; 100 (1 Suppl Spine): 20-3.

5. Wicks AB, Menter RR. Long-term outlook in quadriplegic patients with initial ventilator dependency. Chest 1986; 90: 406-10.

6. Lumb AB. Nunn's applied respiratory physiology. 6th ed. Philladelphia, Elservier Buttoerworth-Heinemann. 2005, pp 430-1.

7. Oo T, Watt JW, Soni BM, Sett PK. Delayed diaphragm recovery in 12 patients after high cervical spinal cord injury. A retrospective review of the diaphragm status of 107 patients ventilated after acute spinal cord injury. Spinal Cord 1999; 37: 117-22.

8. Chiodo AE, Scelza W, Forchheimer M. Predictors of ventilator weaning in individuals with high cervical spinal cord injury. J Spinal Cord Med 2008; 31: 72-7.

9. Kim WY, Suh HJ, Hong SB, Koh Y, Lim CM. Diaphragm dysfunction assessed by ultrasonography: Influence on weaning from mechanical ventilation. Crit Care Med 2011; 39: 2627-30.

10. Mier-Jedrzejowicz A, Brophy C, Green M. Respiratory muscle weak- 
ness during upper respiratory tract infections. Am Rev Respir Dis 1988; 138: 5-7.

11. Bach JR. Update and perspective on non-invasive respiratory muscle aids. Part 2: The expiratory aids. Chest 1994; 105: 1538-44.

12. Tzeng AC, Bach JR. Prevention of pulmonary morbidity forpatients with neuromuscular disease. Chest 2000; 118: 1390-6.
13. Marchant WA, Fox R. Postoperative use of a cough assist device in avoiding prolonged intubation. Br J Anaesth 2002; 89: 644-7.

14. Liszner K, Feinberg M. Cough assist strategy for pulmonary toileting in ventilator-dependent spinal cord injured patients. Rehabil Nurs 2006; 31: 218-21. 